WellBeing International

WBI Studies Repository

3-1994

\title{
The Relationship between Creep Feeding Behavior of Piglets and Adaptation to Weaning: Effect of Diet Quality
}

David Fraser

Agriculture and Agri-Food Canada

J. J.R. Feddes

Agriculture and Agri-Food Canada

E. A. Pajor

Agriculture and Agri-Food Canada

Follow this and additional works at: https://www.wellbeingintlstudiesrepository.org/feebeh

Part of the Animal Studies Commons, Behavior and Ethology Commons, and the Comparative Psychology Commons

\section{Recommended Citation}

Fraser, D., Pajor, E. A., \& Feddes, J. J. R. (1994). The relationship between creep feeding behavior of piglets and adaptation to weaning: effect of diet quality. Canadian Journal of Animal Science, 74(1), 1-6.

This material is brought to you for free and open access by WellBeing International. It has been accepted for inclusion by an authorized administrator of the WBI Studies Repository. For more information, please contact wbisr-info@wellbeingintl.org.

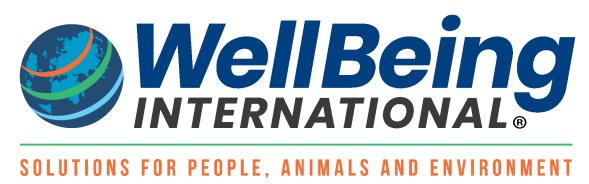




\title{
The Relationship between Creep Feeding Behavior of Piglets and Adaptation to Weaning: Effect of Diet Quality
}

\author{
David Fraser $^{1}$, J.J.R. Feddes ${ }^{1,2}$, E.A. Pajor ${ }^{1}$ \\ ${ }^{1}$ Agriculture and Agri-Food Canada \\ ${ }^{2}$ University of Alberta, Edmonton
}

\begin{abstract}
KEYWORDS
piglets, creep feed, weaning, feeding behavior
\end{abstract}

\begin{abstract}
Individual variation in creep feed intake and its relation to adaptation to weaning were studied in piglets weaned at $4 \mathrm{wk}$ of age. The animals received either a "low-complexity" creep-starter diet based on corn, barley and soybean meal (12 litters), or a "highcomplexity", medicated, commercial diet without soybean meal (12 litters). Diets were fed as creep feed during the $2 \mathrm{wk}$ before weaning, and as the sole diet during the $2 \mathrm{wk}$ after weaning. Creep feeding behavior of piglets was monitored by video recording. Pigs fed the high-complexity diet consumed more creep feed $(P<0.05)$, tended to gain more during the week before weaning $(P<0.10)$, and converted feed more efficiently and gained more weight in the $2 \mathrm{wk}$ after weaning $(P<0.01)$. Use of creep feed varied greatly among individual littermates. Multiple regression analysis showed that on the highcomplexity diet, pigs that used creep feed more than their littermates tended to be those with low gains in weeks $1-3$ after birth $(P<0.001)$, and tended to gain more weight during the week before and during the 2 wk after weaning $(P<0.01)$. The trends were consistent but weaker with the low-complexity diet. However, predictive power was low, with creep feeding accounting for only $4 \%$ of individual variation in post-weaning gain on the high-complexity diet and $1 \%$ on the low. Regardless of diet quality, therefore, creep feeding remained highly variable and only weakly related to weight gains during the 2 wk after weaning.
\end{abstract}

The consumption of supplementary solid "creep feed" before weaning is thought to prepare piglets for a solid, post-weaning diet, and thus promote a more successful adjustment to weaning, even when weaning is as early as 4 wk of age (e.g., VIDO Swine Technical Group 1991). However, the evidence for this benefit is rather sparse, and consists mainly of studies done at the whole-litter level (e.g., English et al. 1980). Such studies typically use whole-litter values for creep feed intake; these values involve 
averaging over the highly variable intakes of individual littermates, and the results need to be interpreted with caution.

A modification of the combined video and electronic recording method of Phillips et al. (1990) has allowed creep feed intakes of individual piglets to be monitored (Pajor et al. 1991). Briefly, the method involves video-recording the use of the feeder by each piglet, combined with electronic monitoring of the amount of food in the dispenser before and after each feeding episode. Subsequent unpublished work showed that for a given litter on a given day, a simple behavioral measure of the time each littermate spent at the creep feeder provided a reasonable estimate of the intake of the animal relative to that of its siblings. This has allowed further studies of how individual creep feed intake is affected by various management options (Appleby et al. 1991, 1992).

In all these studies, members of the same litter often showed very large differences in creep feeding behavior (e.g., ten-fold or greater from highest to lowest), yet piglets with the high feed intake levels showed only a very slight tendency toward more successful adaptation to weaning. For example, with the exception of the occasional piglet that ate very large amounts of creep feed, the piglets' level of creep feeding accounted for only 1\% (Pajor et al. 1991), 3\% (Appleby et al. 1991) and 2\% (Appleby et al. 1992) of variation in weight gains during the first 2 wk after weaning, after litter differences and the effect of antecedent variables (birth weight and early weight gains) had been taken into account.

The weakness of these relationships casts doubt on how effectively creep feed consumption prepares the 4-wk-old piglet for weaning. However, all of these studies used a low-cost creep and starter diet containing $25 \%$ soybean meal. Such diets, although commonly used, are not easily digested by the $3-$ to 4-wk-old piglet. With a diet well suited to the young piglet, creep feed intake might show less extreme variation and a clearer relationship with performance after weaning.

The following study monitored the individual creep feeding behavior and weight gains of piglets fed one of two different diets: a high-complexity, medicated commercial creep-starter diet without soybean meal, or a low-cost alternative using soybean meal as the principal protein supplement. The purpose was to compare the relationship between individual creep feed use and performance, especially after weaning, on the two diets.

\section{MATERIALS AND METHODS}

The study involved 24 litters of eight to 12 piglets from the minimum-disease Yorkshire and Landrace herd at Agriculture Canadas Centre for Food and Animal Research, Ottawa. Before weaning, piglets were housed with the sow in farrowing pens $1.7 \times 2.7 \mathrm{~m}$ with a heated creep area $(0.7 \times 2.7 \mathrm{~m})$ at one side of the sow The creep area was equipped with a water bowl available to the piglets from birth and a wooden creep feed dispenser available during the last $14 \mathrm{~d}$ before weaning. The feed dispenser included two feeding spaces each $95 \mathrm{~mm}$ wide with a 15- $\mathrm{mm}$ rim to prevent spillage. Trays were placed under eight of the feeders to confirm that the rims were effective in reducing spillage to a negligible level. Room lighting (about $100 \mathrm{~lx}$ ) was on from 07:00 to 23:00 h. Minimal night-time lighting (about $10 \mathrm{~lx}$ ) was provided above the creep feeders to allow video recording.

Upon weaning, each litter was moved to a raised weaner pen $1.2 \times 2.4 \mathrm{~m}$ equipped with two nipple drinkers and two feed dispensers, each offering two feeding spaces $130 \mathrm{~mm}$ wide. Trays were placed under each feeder to collect spillage. Room temperature was thermostatically controlled at $29^{\circ} \mathrm{C}$ in the first week after weaning and declined by about $1.5^{\circ} \mathrm{C}$ per week thereafter.

Two diets were used. The "low-complexity" diet was a crumble offering $18.4 \%$ crude protein and consisting of $44 \%$ corn, $25 \%$ soybean meal, $15 \%$ barley and $7 \%$ whey powder, supplemented with 
dicalcium phosphate (2\%), stabilized fat (2\%), limestone (1.3\%), iodized salt (0.4\%), lysine hydrochloride $(0.2 \%)$, a pelleting agent and pre-mixes containing trace minerals and vitamins. The "high-complexity" diet was a proprietary creep-starter diet ( $\mathrm{H}-\mathrm{O}$ Babyboomer Plus, Ralston Purina Canada) formulated using the ideal protein concept and not containing soybean meal in order to reduce allergic reactions. The diet was guaranteed to provide not less than $19 \%$ crude protein and $5 \%$ crude fat, and was medicated with $0.0044 \%$ Tylosin phosphate and $0.02 \%$ furazolidone.

Only litters born on Tuesday to Saturday were included in the experiment so that age at weaning (which, for ease of operation, was done on the Thursday closest to 4 wk of age) was always $28 \pm 2 \mathrm{~d}$. For simplicity, the piglets' first $14 \pm 2 \mathrm{~d}$, from birth until the Thursday when creep feed was first provided, were termed "weeks 1 and 2". Subsequent weeks, always Thursday to Thursday, were numbered 3 and 4 (preweaning), 5 and 6 (post-weaning), and "week 7-pius" for the final $11 \mathrm{~d}$ of the study before the piglets were moved out of the raised pens $25 \mathrm{~d}$ after weaning.

Twelve litters were assigned at random to each of the two dietary treatments. Litters in one treatment received the high-complexity diet offered as creep feed for the $14 \mathrm{~d}$ before weaning and as the weaner diet for $14 \mathrm{~d}$ after weaning. These pigs were then changed to the low-complexity diet for the final $11 \mathrm{~d}$ of the experiment (week 7-plus), as is normal in commercial pig rearing. Pigs on the other treatment received the low-complexity diet throughout.

Piglets were weighed at birth (within $24 \mathrm{~h}$ ), 14 and $7 \mathrm{~d}$ before weaning, on the day of weaning, and at 1 , 4, 7, 14 and $25 \mathrm{~d}$ after weaning. Feed dispensers were weighed on these days to record disappearance of feed, and spillage was deducted. All additions of feed between the weighing days were noted.

Creep feeding behavior was recorded by time-lapse video recording during two 48-h periods covering the last $2 \mathrm{~d}$ (Tuesday to Thursday) in each of weeks 3 and 4 . At the beginning of the period, pigs were numbered with black ink numbers on their backs for identification in the video recordings. Behavior at the feeder was recorded from an overhead camera at a speed of one frame per min. From analysis of the video records, a creep feeding score was derived for each piglet, corresponding to the number of video frames per $24 \mathrm{~h}$ (maximum of 1440) in which the pig had its head in the feeder.

\section{Statistical Analysis}

The relation of creep feeding activity to other variables was studied mainly by multiple linear regression analysis. For testing the within-litter relationship between post-weaning weight gain and creep feeding behavior, measures of post-weaning gains were used as dependant variables and the model included differences between litters as the first variable, followed by birth weight, gain in weeks 1 and 2, and gain in week 3 in chronological order, and then creep feeding score in week 4 (the week when most creep feeding occurred) as the final variable. In case differences between litters in consumption rate affected the relationships, the interaction of litters with the linear regression on creep feeding score was also tested. The analysis was done for the two diets separately, in order to describe the strength of the relationship on each diet. To test whether the relationship differed significantly between the diets, an analysis of covariance was done using all piglets, with a model that included diets, litters (within diets), together with birth weight, gain during weeks 1 and 2, and gain during week 3 as covariates; creep feeding score in week 4 was then introduced as a final covariate, followed by the interaction of diet with the linear regression on creep feeding score. The interaction term was thus a test of whether the diets differed significantly in the regression slope.

A similar approach was used to test other within-litter relationships including (1) whether piglets with low initial weight gains tended to make more use of creep feed, and (2) whether piglet weight gains during 
weeks 3 and 4 were related to creep feeding behavior during those weeks. Relationships between creep feed intake and other variables were also tested on a between-litter basis, by analysis of covariance using the 24 litter means or litter values.

Table 1. Mean ( \pm SEM) performance measures for 12 litters of piglets on the high-complexity diet and 12 litters on the low-complexity diet

\begin{tabular}{|c|c|c|c|}
\hline \multirow[b]{2}{*}{ Variable } & \multicolumn{3}{|c|}{ Diet } \\
\hline & High complexity & Low complexity & $P$ \\
\hline \multicolumn{4}{|l|}{ Body weight $(\mathrm{kg})^{z}$} \\
\hline Birth & $1.4 \pm 0.02$ & $1.4 \pm 0.03$ & NS \\
\hline Weaning & $7.2 \pm 0.16$ & $6.9 \pm 0.14$ & $<0.10$ \\
\hline $25 \mathrm{~d}$ after weaning & $17.4 \pm 0.28$ & $15.7 \pm 0.30$ & $<0.01$ \\
\hline \multicolumn{4}{|c|}{ Gain ${ }^{y}$ before weaning $\left(\mathrm{g} \mathrm{d}^{-1}\right)$} \\
\hline Weeks 1 and 2 & $178 \pm 6$ & $178 \pm 5$ & NS \\
\hline Week 3 & $220 \pm 6$ & $211 \pm 7$ & NS \\
\hline Week 4 & $263 \pm 7$ & $232 \pm 6$ & $<0.10$ \\
\hline \multicolumn{4}{|c|}{ Gain ${ }^{y}$ after weaning $\left(\mathrm{g} \mathrm{d}^{-1}\right)$} \\
\hline Week 5: Day 1 & $-129 \pm 19$ & $-98 \pm 24$ & NS \\
\hline Days 2-4 & $269 \pm 10$ & $137 \pm 11$ & $\approx 0.001$ \\
\hline Days 5-7 & $258 \pm 9$ & $115 \pm 11$ & $<0.001$ \\
\hline Week 6 & $463 \pm 9$ & $315 \pm 12$ & $<0.01$ \\
\hline Week 7-plus & $512 \pm 9$ & $546 \pm 11$ & $<0.001$ \\
\hline \multicolumn{4}{|c|}{ Creep feeding before weaning } \\
\hline Intake ${ }^{\mathrm{x}}$, week $3\left(\mathrm{~g} \mathrm{~d}^{-1}\right)$ & $11 \pm 2.5$ & $5 \pm 1.0$ & $<0.05$ \\
\hline Intake $^{\mathrm{x}}$, week $4\left(\mathrm{~g} \mathrm{~d}^{-1}\right)$ & $44 \pm 9.3$ & $18 \pm 5.4$ & $<0.05$ \\
\hline Score, week $3^{y}$ & $7 \pm 0.8$ & $5 \pm 0.6$ & NS \\
\hline Score, week $4^{y}$ & $16 \pm 1.2$ & $13 \pm 1.6$ & NS \\
\hline SD of score, week $3^{w}$ & $6 \pm 1.4$ & $4 \pm 0.9$ & NS \\
\hline SD of score, week $4^{w}$ & $10 \pm 1.2$ & $9 \pm 2.4$ & NS \\
\hline \multicolumn{4}{|c|}{ Feed intake $\mathrm{x}^{\mathrm{x}}$ after weaning $\left(\mathrm{g} \mathrm{d}^{-1}\right)$} \\
\hline Week 5: Day 1 & $134 \pm 20$ & $142 \pm 30$ & NS \\
\hline Days 2-4 & $249 \pm 21$ & $178 \pm 22$ & $<0.05$ \\
\hline Days 5-7 & $271 \pm 20$ & $255 \pm 18$ & NS \\
\hline Week 6 & $530 \pm 21$ & $439 \pm 36$ & $<0.05$ \\
\hline Week 7 & $873 \pm 37$ & $851 \pm 37$ & NS \\
\hline \multicolumn{4}{|c|}{ Gain: intake ${ }^{\mathrm{x}}$ after weaning $\left(\mathrm{g} \mathrm{g}^{-1}\right)$} \\
\hline Week 5 & $0.83 \pm 0.04$ & $0.42 \pm 0.09$ & $<0.001$ \\
\hline Week 6 & $0.88 \pm 0.02$ & $0.73 \pm 0.04$ & $<0.01$ \\
\hline Week 7-plus & $0.60 \pm 0.02$ & $0.67 \pm 0.02$ & $<0.05$ \\
\hline
\end{tabular}

${ }^{z}$ For descriptive purposes, unadjusted means and standard errors, based on $n \approx 115$ piglets per treatment, are shown. In the statistical analysis, weights were adjusted for the previous weight(s) and gains during weeks 1 and 2 , before testing the effect of diet.

${ }^{y}$ For descriptive purposes, unadjusted means and standard errors, based on $n \approx 115$ piglets per treatment, are shown. In the statistical analysis, values were adjusted for birth weight and for gain in all previous periods before testing the effect of diet.

${ }^{x}$ Means and standard errors are based on $n=12$ litters per treatment. Significance levels are based on unadjusted values. Adjustment for mean birth weight and mean weight at start of creep feeding had little effect.

${ }^{w}$ Mean \pm SEM of the within-litter standard deviation in creep feeding score during weeks 3 and 4 , based on $n=12$ litter values per treatment. 
The effects of diet on body weights and weight gains were tested by analysis of covariance with a model that included diets ( 1 d.f.) tested against litters within diets (23 d.f.), after adjustment for one or more covariates as detailed in Table 1. A simple two-way analysis of variance (for diets and litters) was used to test differences in those variables (feed intake, feed conversion efficiency) that were measured at the whole-litter level.

\section{RESULTS AND DISCUSSION}

\section{Effect of Diet on Performance}

As expected, the two diets had very different effects on piglet performance. Pigs in the two treatments did not differ in birth weight or gain during weeks 1 and 2, before the diets were offered (Table 1), but pigs on the high-complexity diet tended to have greater weaning weights $(P<0.10)$ and had significantly greater weights $25 \mathrm{~d}$ after weaning $(P<0.01)$. Diet had little effect on weight gain in week 3 when creep feed was first offered (Table 1), but gains on the high-complexity diet averaged $31 \mathrm{~g} \mathrm{~d}^{-1}$ more than on the lowcomplexity diet in week $4(P<0.10)$. Pigs ate significantly more of the high-complexity diet than of the low-complexity diet during both weeks 3 and 4 (Table 1). On the first day after weaning, weight change was extremely variable, piglets lost weight on average, and there was no apparent difference between dietary treatments. During the rest of week 5 and during week 6 , pigs on the high-complexity diet gained significantly more than those on the low-complexity diet, showed greater feed conversion efficiency, and tended to eat more, the difference in intake being significant $(P<0.05)$ during two of the four periods (Table 1). The greater consumption of the high-complexity diet before weaning, combined with greater gains and feed conversion efficiency after weaning, appear to be typical of results with high-complexity diets designed to be readily digestible by young pigs (e.g., Okai et al. 1976; Tokach et al. 1990).

During week 7-plus, when all pigs were fed the low-complexity diet, those that had received this diet from the beginning had greater gains and greater feed conversion efficiency than those that had just changed from the high-complexity diet (Table 1). The mild set-back experienced by pigs when switched from the high- to the low-complexity diet, suggests that for practical purposes, gradual introduction of the lowcomplexity diet might be advisable.

Regardless of the diet, individual littermates still showed extremely large variation in creep feed use as evidenced by the large standard deviations in creep feeding scores (Table 1). The diets did not differ significantly in the amount of within-litter variation for any of the body weight or gain measures.

\section{Creep Feeding Behavior and Intake}

As a check on the validity of the behavioral creep feeding score, the regression was calculated for the litters' actual creep feed consumption (average weight loss from the feeder per pig per day, during the 14 $d$ before weaning) versus their mean creep feeding scores (video frames of feeding behavior per pig per day, during the $4 \mathrm{~d}$ of video recording). The two measures were highly correlated, with 12 values of 0.86 and 0.87 for the high- and low-complexity diets, respectively. The slope of the linear regression through the origin (Fig. 1) was significantly greater for the high-complexity diet ( $2.5 \pm 0.2$, slope \pm SE) than for the low $(1.3 \pm 0.1)$, indicating that piglets consumed about twice as much of the pelleted high-complexity diet per unit of feeding time. As the high-complexity diet was only slightly more dense than the low-complexity diet $\left(750\right.$ versus $\left.650 \mathrm{~g} \mathrm{~L}^{-1}\right)$, the difference in slopes indicated a greater volume intake, as well as a greater weight intake, per unit of feeding time with the high-complexity diet.

The diurnal pattern of creep feeding differed somewhat between diets. On the low-complexity diet, feeding activity was concentrated in three periods: 08:00-10:00 $\mathrm{h}$ when staff arrived in the rooms. 11:0014:00 $\mathrm{h}$ when sows were fed and management activities were common, and 21:00-23:00 $\mathrm{h}$ before the 
lights were turned out, with only $13 \%$ of feeding activity during night-time hours of 23:00-07:00 h. For pigs on the high-complexity diet, feeding was less highly concentrated into distinct periods and $22 \%$ of feeding activity occurred at night; this is more similar to the distribution of feed intake of mature pigs (e.g., Fraser et al. 1991).

Fig. 1. Creep feed consumption (measured by disappearance of weight from the feeder and expressed per pig per day over weeks 3 and 4 ) and mean creep feeding score (measured by video recording during weeks 3 and 4) for 12 litters on the high-complexity diet (solid circles) and 12 on the low (open circles). Regression lines through the origin are shown for each diet. Slopes are $2.5 \pm 0.2$ and $1.3 \pm 0.1$ for the high- and lowcomplexity diets respectively.

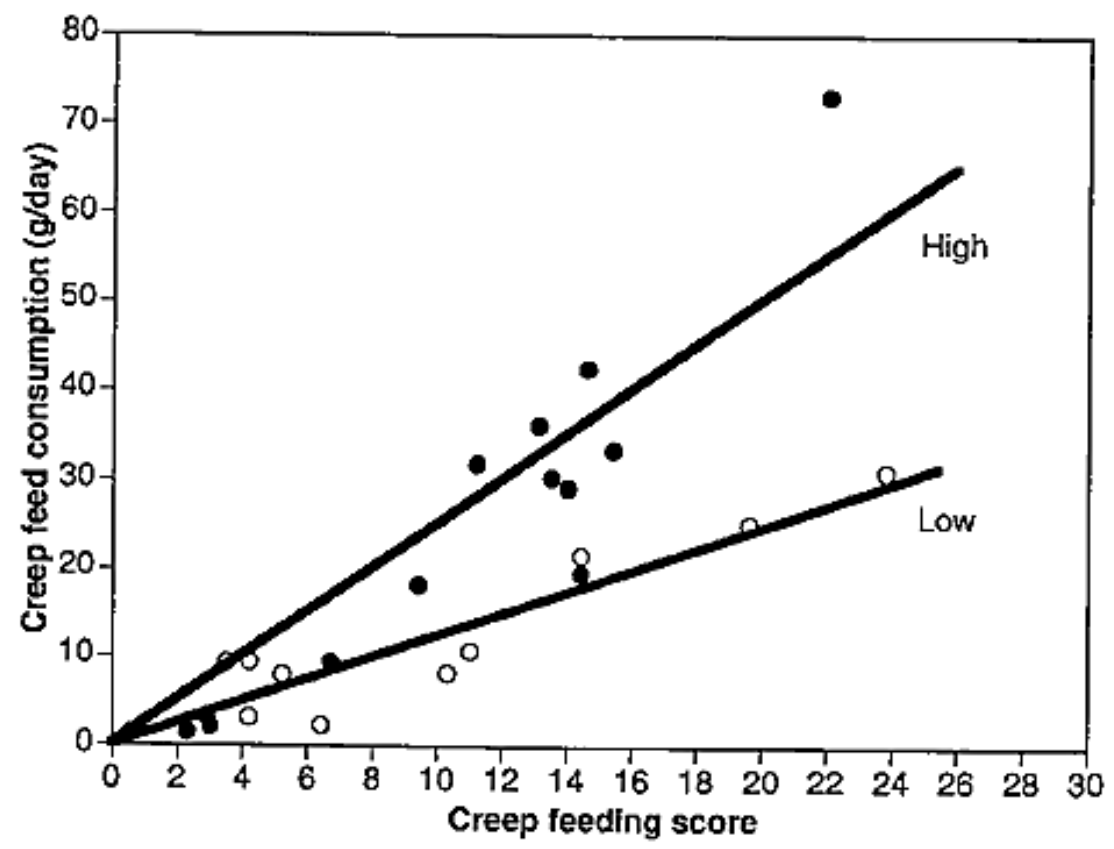

\section{Creep Feeding in Relation to Earlier Weight Gain}

Within litters, piglets that had previously gained less weight than their littermates tended to use creep feed more, but this trend was much clearer with the high-complexity diet than with the low. Multiple linear regression was used to determine the relationship between creep feeding scores, during weeks 3 and 4 separately, and antecedent variables (Table 2). With the high-complexity diet, weight gains during weeks 1 and 2 accounted for $11 \%$ of variation in creep feeding score during week $3(P<0.001)$, and weight gains during weeks 1 and $2(P<0.001)$ and during week $3(P<0.01)$ jointly accounted for $11 \%$ of variation in creep feeding score during week 4 . With the low-complexity diet, the relationship was weaker in week 4 and non-existent in week 3 (Table 2). In an analysis of covariance of the entire data set, with creep feeding score during week 3 as dependent variable, there was a significant interaction between diet and the regression on gain during weeks 1 and $2(P<0.05)$ indicating a significant difference between diets in the relationship between creep feeding and early gain. In a similar analysis of creep feeding score during week 4, the interaction of diet and early gain was not significant. Thus, with the high-complexity diet, there was a stronger tendency for piglets with the lowest early weight gains to feed more on creep feed in an apparently compensatory manner. Nonetheless, the effect was not sufficient to make weaning weights more uniform on the high-complexity diet. Between-litter analysis, based on the $24 \mathrm{~h}$ litter values for feed intake, showed little tendency for litters with low early gains to consume more creep feed on either diet. 
Creep feeding seems to begin largely as an exploratory and social activity and then become more driven by nutrient demand as the pig matures (Pajor et al. 1991). The greater evidence of compensatory creep feeding on the high-complexity diet suggests that this maturational process may have been more advanced with the diet that was better suited to the young pig.

Table 2. Multiple linear regression analysis of piglets' creep feeding scores during weeks 3 and 4 for piglets on the high- and low-complexity diet

\begin{tabular}{|c|c|c|c|c|c|}
\hline \multirow[b]{2}{*}{ Step $^{2}$} & \multirow[b]{2}{*}{ Variable } & \multicolumn{2}{|c|}{ High-complexity diet } & \multicolumn{2}{|c|}{ Low-complexity diet } \\
\hline & & Partial $r^{2}$ & $P$ & Partial $r^{2}$ & $P$ \\
\hline \multicolumn{6}{|c|}{ Creep feeding score, week 3} \\
\hline 1 & Litter & 0.28 & $<0.001$ & 0.37 & $<0.001$ \\
\hline 2 & Birth weight & 0.00 & NS & 0.01 & NS \\
\hline 3 & Gain, weeks 1 and 2 & $0.11^{y}$ & $<0.001$ & 0.00 & NS \\
\hline \multicolumn{6}{|c|}{ Creep feeding score, week 4} \\
\hline 1 & Litter & 0.38 & $<0.001$ & 0.55 & $<0.001$ \\
\hline 2 & Birth weight & 0.00 & NS & 0.00 & NS \\
\hline 3 & Gain, weeks 1 and 2 & $0.07^{y}$ & $<0.001$ & 0.01 & NS \\
\hline 4 & Gain, week 3 & $0.04^{y}$ & $<0.01$ & $0.02^{y}$ & $<0.05$ \\
\hline
\end{tabular}

${ }^{z}$ In this and subsequent tables, the order of variable entry into the model was pre-determined, with litter differences entered first and other variables included in chronological order.

${ }^{y}$ Partial correlation coefficients were negative, indicating greater creep feeding by piglets with low early weight gains.

\section{Relation of Creep Feeding Behavior to Pre-weaning Gain}

Creep feeding appeared to make some contribution to pre-weaning gain. The effect was clearer in the between-litter analysis which showed that litters that ate more creep feed in week 4 tended to gain more in that week. Analysis of covariance of the 24 litter means showed that creep feed intake in week 4 accounted for $28 \%$ of variation in weight gain in week $4(P<0.001)$ after differences attributable to diet, birth weight, and weight gain in weeks 1 to 3 had been taken into account, with no interaction of diet and the regression on creep feed intake.

In the within-litter analysis, with the high-complexity diet there was a small but significant tendency for piglets with high creep feeding scores to gain more weight in week 4. Multiple linear regression analysis of piglet body weight gains during week 4 (Table 3) showed that with the high-complexity diet, creep feeding score in week 4 accounted for $3 \%$ of variation $(P \approx 0.001)$ after differences attributable to litters and antecedent variables (birth weight, gain in weeks 1 and 2 , and gain in week 3 ) had been taken into account. For piglets on the low-complexity diet, the relation between gain in week 4 and creep feeding score in week 4 was not significant (Table 3); however, there was a small but significant interaction of litters with the linear regression on creep feeding score $(P \approx 0.05)$ because this regression was stronger for those litters that ate the most creep feed. There was no evidence of a similar relationship between piglet body weight gain in week 3 and creep feeding score in that week.

These results agree with previous findings (English et al. 1980; Pajor et al. 1991; Appleby etal.1992) that creep feeding makes a detectable contribution to weaning weight at 4 wk. With later weaning, the effect of creep feed on body weight is usually clear by the age of 5 wk or more (e.g., Aumaitre and SalmonLegagneur 1961; Friend et al. 1970 Aherne et al. 1982; but not Okai et al. 1976). 
Table 3. Multiple linear regression analysis of piglet body weight gains during week 4 (the week before weaning) for piglets on the high- and low-complexity diet

\begin{tabular}{|llccccc|}
\hline & & \multicolumn{2}{c}{ High-complexity diet } & & \multicolumn{2}{c|}{ Low-complexity diet } \\
\cline { 3 - 4 } Step $^{z}$ & Variable & Partial $\boldsymbol{r}^{2}$ & $\boldsymbol{P}$ & & \multicolumn{2}{c|}{ Partial $\boldsymbol{r}^{\mathbf{2}}$} \\
\hline 1 & Litter & 0.56 & $<0.001$ & & 0.22 & $<0.001$ \\
2 & Birth weight & 0.08 & $<0.001$ & & 0.07 & $<0.001$ \\
3 & Gain, weeks 1 and 2 & 0.04 & $<0.001$ & & 0.03 & $<0.05$ \\
4 & Gain, week 3 & 0.06 & $<0.001$ & & 0.17 & $<0.001$ \\
5 & Creep feeding score, week 4 & 0.03 & $\approx 0.001$ & & 0.00 & $\mathrm{NS}$ \\
\hline
\end{tabular}

Table 4. Multiple linear regression analysis of piglet body weight gains during weeks 5 and 6 (the 2 wk after weaning) for piglets on the high- and low-complexity diet

\begin{tabular}{|llcccc|}
\hline & & \multicolumn{2}{c}{ High-complexity diet } & & \multicolumn{2}{c|}{ Low-complexity diet } \\
\cline { 3 - 4 } Step $^{z}$ & Variable & Partial $\boldsymbol{r}^{\mathbf{2}}$ & $\boldsymbol{P}$ & & Partial $\boldsymbol{r}^{\mathbf{2}}$ \\
\hline 1 & Litter & 0.38 & $<0.001$ & $<0.001$ \\
2 & Birth weight & 0.10 & $<0.001$ & $\approx 0.01$ \\
3 & Gain, weeks 1 and 2 & 0.02 & $<0.05$ & $<0.001$ \\
4 & Gain, week 3 & 0.01 & $\mathrm{NS}$ & $<0.001$ \\
5 & Creep feeding score, week 4 & 0.04 & $<0.01$ & $\approx 0.05$ \\
\hline
\end{tabular}

\section{Relation of Creep Feeding Behavior to Performance after Weaning}

On both diets, the link between creep feed intake and adaptation to weaning was weak. The betweenlitter analysis (i.e., analysis of covariance of the litter values) showed no tendency for litters that had eaten the most creep feed to gain more in weeks 5 and 6 or week 7-plus, to consume more feed in these periods, or to convert feed more efficiently. The more sensitive within-litter analysis showed that with both diets, there was a small but significant tendency for piglets with high creep feeding scores to gain more weight than their littermates during the 2 wk after weaning. Multiple linear regression analysis of piglet weight gains in weeks 5 and 6 (Table 4) showed that creep feeding score in week 4 accounted for $4 \%$ of variation with the high-complexity diet $(P<0.01)$ and $1 \%$ of variation with the low-complexity diet $(P=$ $0.05)$, after litter differences and antecedent variables had been taken into account. In a similar analysis of both diets combined, there was no significant interaction between diet and the linear regression of gain during weeks 5 and 6 on creep feeding score in week 4 . The small magnitude of the effect is similar to our previous findings (Pajor et al. 1991; Appleby et al. 1991, 1992).In other studies with 4- or 5-wk weaning, post-weaning performance of pigs that had been raised with or without creep feeding has generally shown small or negligible differences (Okai et al. 1976; Aherne et al. 1982; Barnett et al. 1989; but see English et al. (1980) for an exception). Between 3 and 5 wk of age, piglets show rapid developmental changes in secretion of digestive enzymes (Aumaitre 1972), with large differences between individual piglets (de Passillé et al. 1989), and only limited effects of creep feed intake on enzyme levels (e.g. Friend et al. 1970, Shields et al. 1980). These findings presumably help to explain the limited relationship between creep feed intake and adaptation to weaning.

\section{CONCLUSIONS}

The results indicate that even with a high-complexity diet, which promotes greater creep feed consumption and is converted efficiently by the young pig, creep feed intake varies widely between littermates and, within the range of intakes found in this study, shows no strong relationship to success in adaptation to weaning at 4 wk of age. The results suggest that the advantage of providing creep feed lies 
more in its tendency to increase weaning weight than in any major improvement in the piglets' adjustment to weaning.

\section{ACKNOWLEDGEMENTS}

We are grateful to students P. Berlanga and O. Kretzmer for their work on this experiment, and to the staff of the Centre for Food and Animal Research pig unit for their usual excellent cooperation. Drs. E. R. Farnworth and N. A. G. Cave made helpful comments on the manuscript. E. A. Pajor was supported by grants from Manitoba Pork and from the Agriculture Canada/NSERC Research Partnership Support Program to Dr. D. L. Kramer, Department of Biology, McGill University. Mention of a manufacturer's name in the text is not to be taken as endorsement of a product by Agriculture Canada.

\section{REFERENCES}

Aherne, F. X., Danielsen, V. and Nielsen, H. E, 1982. The effects of creep feeding on pre- and postweaning pig performance. Acta Agric. Scand. 32: 155-160.

Appleby, M. C., Pajor, E. A. and Fraser, D. 1991. Effects of management options on creep feeding by pigiets. Anim. Prod. 53: 361-366.

Appleby, M. C., Pajor, E. A. and Fraser, D. 1992. Individual variation in feeding and growth of piglets: Effects of increased access to creep food. Anim. Prod. 55: 147-152.

Aumaitre, A. 1972. Development of enzyme activity in the digestive tract of the suckling pig: Nutrition significance and implications for weaning. World Rev. Anim. Prod. 8: 54-68.

Aumaitre, A. and Salmon-Legagneur, E. 1961. Influence de l'alimentation complémentaire sur la croissance du porcelet avant le sevrage. Ann. Zootech. 10: 127-140.

Barnett, K. L., Kornegay, E. T., Risley, C. R,, Lindemann, M. D. and Schurig, G. G. 1989. Characterization of creep feed consumption and its subsequent effects on immune response, scouring index and performance of weanling pigs. J. Anim. Sci. 67: 2698-2708.

de Passillé, A. M. B., Pelletier, G., Ménard, J. and Morisset, J. 1989. Relationships of weight gain and behavior to digestive organ weight and enzyme activities in piglets. J. Anim. Sci. 67: 2921-2929.

English, P. R., Robb, C. M. and Dias, M. F. M. 1980. Evaluation of creep feeding using a highly-digestible diet for litters weaned at 4 weeks of age. Anim. Prod. 30: 496. (Abstr.)

Fraser, D., Phillips, P. A., Thompson, B. K. and Tennessen, T. 1991. Effect of straw on the behaviour of growing pigs. Appl. Anim. Behav. Sci. 30: 307-318.

Friend, D.W., Gorrill, A. D. I. and Maclntyre, T. M. 1970. Performance and proteolytic enzyme activity of the suckling piglet creep-fed at one or three weeks of age. Can. J. Anim. Sci. 50: 349-354.

Okai, D. B., Aherne, F. X. and Hardin, R. T. 1976. Effects of creep and starter composition on feed intake and performance of young pigs. Can. J. Anim. Sci. 56: 573-586.

Pajor, E. A., Fraser, D. and Kramer, D. L. 1991. Consumption of solid food by suckling pigs: Individual variation and relation to weight gain. Appl. Anim. Behav. Sci. 32: 139-155. 
Phillips, P. A., Fraser, D., Leclerc, J.-M. and Thompson, B. K. 1990. Measurement of individual water intake by group-housed piglets. Trans. ASAE 33: 912-916.

Shields, R. G., Jr., Ekstrom, K. E. and Mahan, D. C. 1980. Effect of weaning age and feeding method on digestive enzyme development in swine from birth to ten weeks. J. Anim. Sci. 50: 257-265.

Tokach, M. D., Pettigrew, J. E., Johnston, L. J. and Cornelius, S. G. 1990. Overall performance to market weight is improved by adding milk products, but not fat, to the starter diet. J. Anim. Sci. 68 (Suppl. 1): 377. (Abstr.)

VIDO Swine Technical Group. 1991. Swine nursery design and management. 2nd ed. Veterinary Infectious Disease Organization, Saskatoon, SK. 